\title{
A New Environmentally-Friendly Colorimetric Probe for Formaldehyde Gas Detection under Real Conditions
}

\author{
Carlos Martínez-Aquino ${ }^{1}$, Ana M. Costero ${ }^{1,2,3, * \mathbb{C}}$, Salvador Gil ${ }^{1,2,3}$ and Pablo Gaviña ${ }^{1,2,3}$ \\ 1 Instituto Interuniversitario de Investigación de Reconocimiento Molecular y Desarrollo Tecnológico (IDM). \\ Universitad Politècnica de València, Universitat de València, Doctor Moliner 50, Burjassot, 46100 Valencia, \\ Spain; carlos.martinez-aquino@uv.es (C.M.-A.); Salvador.Gil@uv.es (S.G.); pablo.gavina@uv.es (P.G.) \\ 2 Departamento de Química Orgánica, Universitat València, Doctor Moliner 50, Burjassot, \\ 46100 Valencia, Spain \\ 3 CIBER de Bioingeniería, Biometariales y Nanomedicina (CIBER-BBN), Spain \\ * Correspondence: Ana.Costero@uv.es; Tel.: +34-963544410
}

Received: 18 September 2018; Accepted: 15 October 2018; Published: 16 October 2018

\begin{abstract}
A new environmentally-friendly, simple, selective and sensitive probe for detecting formaldehyde, based on naturally-occurring compounds, through either colorimetric or fluorescence changes, is described. The probe is able to detect formaldehyde in both solution and the gas phase with limits of detection of $0.24 \mathrm{mM}$ and $0.7 \mathrm{ppm}$, respectively. The probe has been tested to study formaldehyde emission in contaminated real atmospheres. The supported probe is easy to use and to dispose, and is safe and suitable as an individual chemodosimeter.
\end{abstract}

Keywords: formaldehyde; chromogenic sensor; gas phase; environmentally-friendly; Pictet-Spengler

\section{Introduction}

Formaldehyde is one of the most widely used compounds in the chemical industry, with a global production higher than 52 million tons/year [1]. Most formaldehyde produced is used for the manufacture of formaldehyde-based resins for pressed wood products, such as particleboard, panels or furniture. Formaldehyde is also widely used in medical laboratories, mortuaries, and in some personal care and consumer products for its preservative and anti-bacterial properties. It is also a by-product in the combustion of organic compounds and thus is present at lower levels in outdoor air because of forest fires, automobile exhaust, tobacco smoke and other combustion sources, such as woodstoves or refineries. However, the highest concentration levels are found in work settings where formaldehyde is used or produced.

It has been reported [2] that exposure to 2-10 ppm of formaldehyde produces almost immediate eye irritation and a sharp burning sensation of the nose and throat which may be associated with sneezing, difficulty in taking a deep breath, and coughing; recovery is prompt from these transient effects, whereas exposure for 5 to $10 \mathrm{~min}$ to 25 to $100 \mathrm{ppm}$ might cause serious injury to the lower respiratory passages [3]. Moreover, in 2011, the United States National Toxicology Program included formaldehyde in the list of known human carcinogens [4].

Detection of formaldehyde is usually done by using different techniques such as spectrophotometry [5], HPLC [6], laser induced fluorescence spectroscopy [7] capillary electrophoresis [8], conductometry [9-11] and enzyme-based biosensors [12-14]. However, these methods still show certain limitations such as limited selectivity and reliability in the presence of interferents, operational complexity, non-portability or difficulties in real-time monitoring. The use of chromogenic or fluorogenic chemosensors allows sidestep some of these limitations. In fact several colorimetric and fluorometric methods for detecting 
formaldehyde are described in the literature [15]. Many of these methods are directed toward detecting it in tissues, cells, or even in animal organs [16-21]. There are also several examples that detect this aldehyde dissolved in different solvents, such as water, methanol or DMF [22-27]. However, very few colorimetric or fluorometric sensors detect formaldehyde gas. Le Calvé et al. [28] described a colorimetric sensor based on the Hantzsh reaction using a microfluidic system. Even though the limits of detection were good, the authors reported neither the time of detection nor selectivity when faced with possible interferents. In addition, the microfluidic system was neither portable nor easy to use. In $2016 \mathrm{Wu}$ et al. [29] reported the use of a Cd-Te Qdots array with good sensitivity, but the system was clearly more pollutant than that developed in this manuscript. Suslick [30] reported in 2010 the detection of formaldehyde gas with a good limit of detection and appropriate selectivity by also using a colorimetric array. The array used 25 colorants which, despite being slightly pollutant, made the final product more expensive. Gou et al. described the use of 4-aminohydrazine-5-mercapto-1,2,4-triazole for sensing formaldehyde gas [31]. The sensing reaction took place in solution in a reservoir included in a three-dimensional microfluidic chip. Lin et al. [32] indicated the use of a rhodamine derivative supported on filter paper with different applications. These authors mentioned the possibility of using the sensor indoors, but their work was based on a sole and poorly described observation. Mahapatra el al. [33] reported employing another heterocycle that, supported in TLC, worked with good selectivity and sensitivity. This work was published in 2018, which indicates that the preparation of supported sensors for formaldehyde is a hot research area. Also in 2018, Wei et al. reported a formaldehyde sensor based on the aggregation-induced emission (AIE) effect [34]. In this case, the probe contained a complex structure and needed bismuth salts to detect the analyte. The authors indicated that the probe could be used in the gas phase, but the described experiments are mostly related to detection in solution.

Given the interest shown in detecting formaldehyde in the gas phase, we decided to develop a simple, easy-to-use and environmentally-friendly probe. The probe described herein, compared to the aforementioned methods, presents some advantages (for further details, see Table S1 in the Supplementary Materials).

The Pictet-Spengler [35] reaction of primary catecholamines with formaldehyde followed by aerobic oxidation of the generated tetrahydroisoquinoline has been used for the histochemical demonstration of biogenic monoamines by using fluorescence microscopy [36]. We now report the application of this process, which uses environmentally-friendly compounds, for detecting formaldehyde. The sensing protocol is shown in Scheme 1.

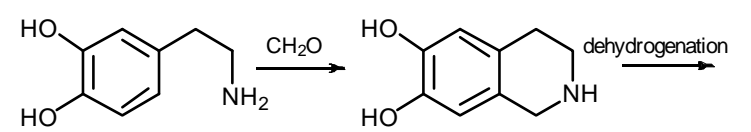

colorless, not fluorescent

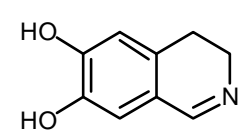

yellow, fluorescent

Scheme 1. Chromo-fluorogenic sensing of formaldehyde with dopamine by using the Pictet-Spengler reaction.

\section{Results and Discussion}

Even though our primary interest was formaldehyde detection in gas phase, sensing experiments with the analyte in aqueous solution were developed to optimize the reaction conditions. The sensor probe consists of a $10^{-3} \mathrm{M}$ aqueous solution of dopamine, containing sucrose and glycine (0.06 and 0.1 equiv respectively) at $\mathrm{pH} 8.0$ (phosphate buffer). We decided to use the mixture of sucrose and glycine following the conditions of the original work by Bjorklund, et al. [37]. In addition, $\mathrm{pH}$ was adjusted to 8.0 to obtain a better emission response. It is known that at this $\mathrm{pH}$, the dihydroisoquinoline exists predominantly in its tautomeric quinoidal form, which seems to be responsible for its intense fluorescence [36]. We found that glycine was necessary to catalyze the reaction at this $\mathrm{pH}$ [38]. In fact, in experiments performed in the absence of glycine no colorimetric response was observed in the presence of formaldehyde. With respect to the use of sucrose, we found that its presence was not 
necessary for the reaction to proceed, although it slightly enhanced the response of the probe (probably through hydrogen bonding).

When excess aqueous formaldehyde (formalin 36\%) was added to the probe, a yellow colour was observed within $2 \mathrm{~min}$. The observed colour was due to a new absorption band at $\lambda=420 \mathrm{~nm}$ in the UV-vis spectrum (Figure 1A). Also strong changes in the fluorescent properties of the mixture were observed in the presence of the target molecule. Thus, an intense fluorescence emission at $\lambda_{\mathrm{em}}=485 \mathrm{~nm}$ was observed when the mixture with formaldehyde was irradiated at $\lambda_{\mathrm{exc}}=420 \mathrm{~nm}$ (Figure 1B). All these changes can be ascribed to the one pot reaction shown in Scheme 1.

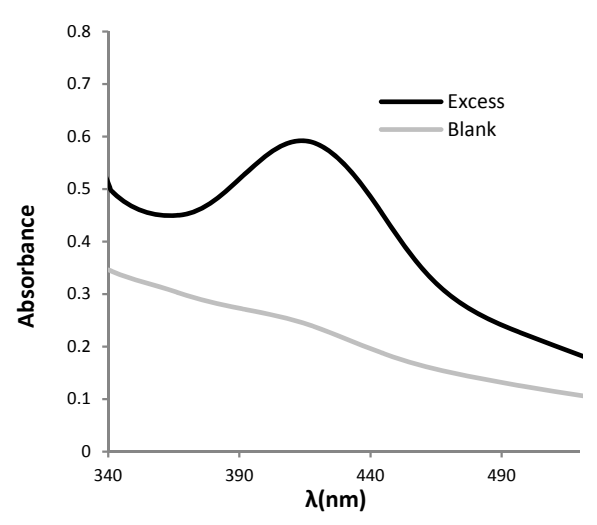

(A)

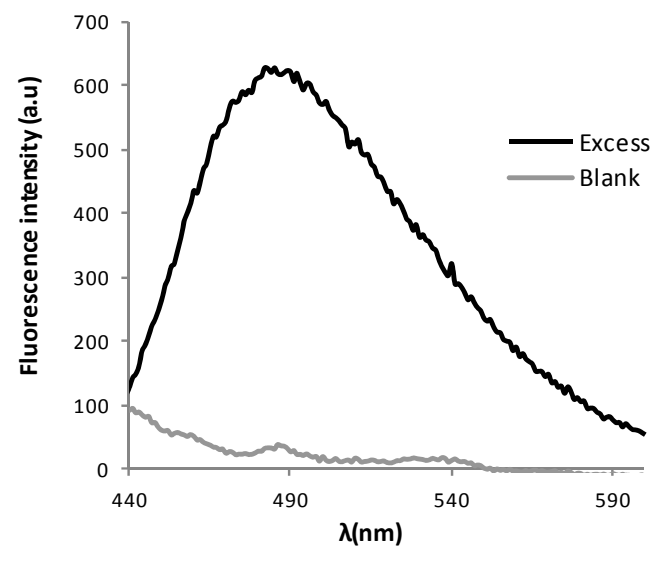

(B)

Figure 1. (A) Changes in the UV-vis spectrum of the probe $\left(10^{-3} \mathrm{M}\right.$ in phosphate buffer $\left.\mathrm{pH}=8\right)$ after addition of formaldehyde $(67 \mathrm{mM})$. (B) Fluorescence spectra of the probe (blank) and the probe in presence of excess formaldehyde $\left.(67 \mathrm{mM}) \lambda_{\mathrm{em}}=485 \mathrm{~nm} \lambda_{\mathrm{exc}}=420 \mathrm{~nm}\right)$.

In order to evaluate the applicability of this system for the detection of formaldehyde in water, fluorescence titration experiments with increasing concentrations of formaldehyde (from 0.5 to $67 \mathrm{mM}$ ) were undertaken (see Figure 2).

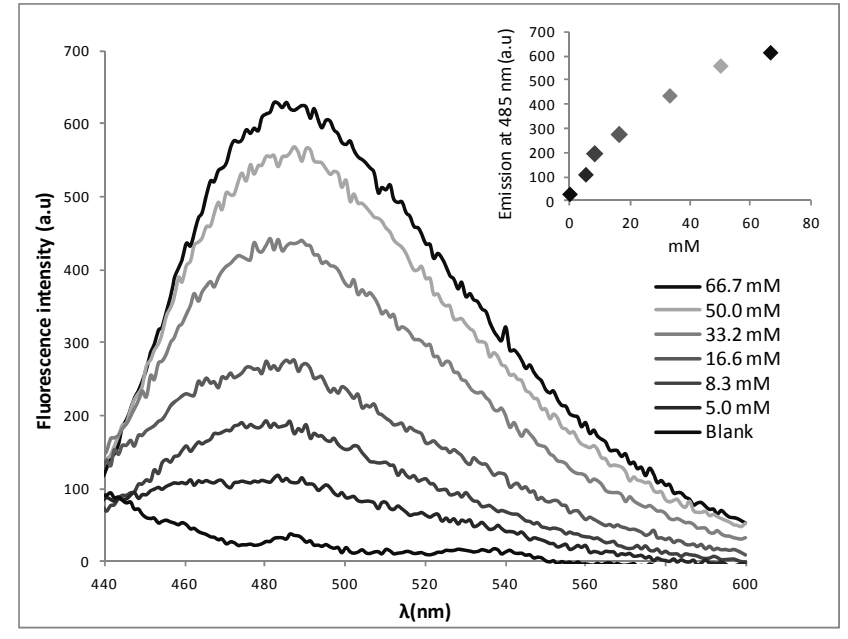

(A)

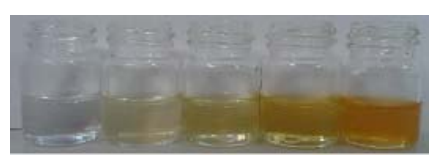

(B)

Figure 2. (A) Fluorescence emission of the probe $\left(10^{-3} \mathrm{M}\right.$ in buffered water at $\left.\mathrm{pH} 8.0\right)$ in presence of increasing amounts of formaldehyde. Inset: Plot of the fluorescence intensity at $485 \mathrm{~nm}$ versus formaldehyde concentration. (B) Visual colour changes observed under the same conditions (from left to right $0,5,16.6,66.7$ and $150 \mathrm{mM})$.

We observed that at concentrations above $80 \mathrm{mM}$, turbidity appeared in the solution indicating the presence of some precipitate. Limits of detection $(\mathrm{LoD})$ were determined from the equation: 
$\mathrm{LoD}=3 \mathrm{~S}_{\mathrm{b} 1} / \mathrm{S}$, where $\mathrm{S}_{\mathrm{b} 1}$ is the standard deviation of the blank solution and $\mathrm{S}$ is the slope of the calibration curve. The determined LoD was $0.24 \mathrm{mM}$ (see Supplementary Materials).

Formaldehyde dissolves easily in water but the gas does not remain in water for a long time and, for this reason, it is generally not detected in potable water supplies. However, as the presence of formaldehyde in air is ubiquitous, detection of this compound in gas phase is a point of crucial interest. For this reason, we decided to take a further step and extend the probe applicability by preparing test strips for the colorimetric detection of formaldehyde gas (Figure 3).

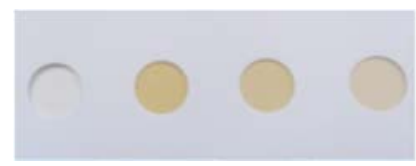

Figure 3. Silica gel supported probes in presence of increasing amounts of formaldehyde gas for 30 min (from left to right $0,40,16$ and 8 ppm of formaldehyde).

The sensor in the absence of the gas was employed as a control, and it showed minor colour variations throughout the experiments. After an exposure period of $30 \mathrm{~min}$ in the presence of the analyte, a chromogenic change from white to yellow was clearly observed in the plates. In order to quantify the amount of formaldehyde and determine the limit of detection of the supported probe, a scanner was used to obtain pictures of the plates. Then RGB coordinates were measured from the photographs using image-processing software (ImageJ). Different values were obtained by the difference of the red, green and blue (RGB) of each plate and the values measured in the control plate. As the greatest differences between the blank and the probe were observed in the blue coordinate, this value was used to determine the LODs (see Supplementary Materials for more details).

Formaldehyde exposure limits (PEL) are expressed in two ways: a short-term exposure limit (STEL) which is the maximum exposure allowed during a 15-min period or a long-term PEL measured as an 8-h time weighted average (TWA). The STEL and 8-h TWA PEL values for gaseous formaldehyde established by NIOSH are 2 and 1 ppm respectively [2]. For this reason, limits of detection of the prepared probe for both STEL (30 $\mathrm{min}$ ) and 10-h TWA in gas phase were determined by exposing the probe to different concentrations of gaseous formaldehyde for $30 \mathrm{~min}$ and $10 \mathrm{~h}$ respectively. The obtained values were 0.7 and $0.4 \mathrm{ppm}$ respectively (see Supplementary Materials). Probe saturation for formaldehyde in gas phase was observed at $40 \mathrm{ppm}$. The probe sensibility seems to be higher for formaldehyde in gas phase than in solution. However, both methods are not strictly comparable.

To demonstrate the selectivity of the probe, interference studies were performed using different VOCs. Thus, the chemodosimeter was exposed for $30 \mathrm{~min}$ to vapour of methanol, acetone, toluene, acetaldehyde, benzaldehyde, $\mathrm{CO}_{2}$, formaldehyde and a mixture of them. As can be seen in Figure 4, only the mixtures with formaldehyde showed a visual response.

Once demonstrated the selective response of the probe for formaldehyde gas, the potential use of the test strips to monitor its presence in more realistic conditions was also tested. Thus, plates containing the probe were placed in the dissection room at the Faculty of Medicine of the University of Valencia in two different weeks (with and without corpses preserved with formalin). The probes were removed after 24 and $48 \mathrm{~h}$. Colour changes increase with time in both cases (with and without corpses preserved with formalin). Moreover, the changes in colour of the probe exposed to the corpses for $48 \mathrm{~h}$ were clearly observed by the naked eye. The percentage of variation of the blue component with respect to the blank probe was determined in each case following the protocol described in the Supporting Information (Table 1). 


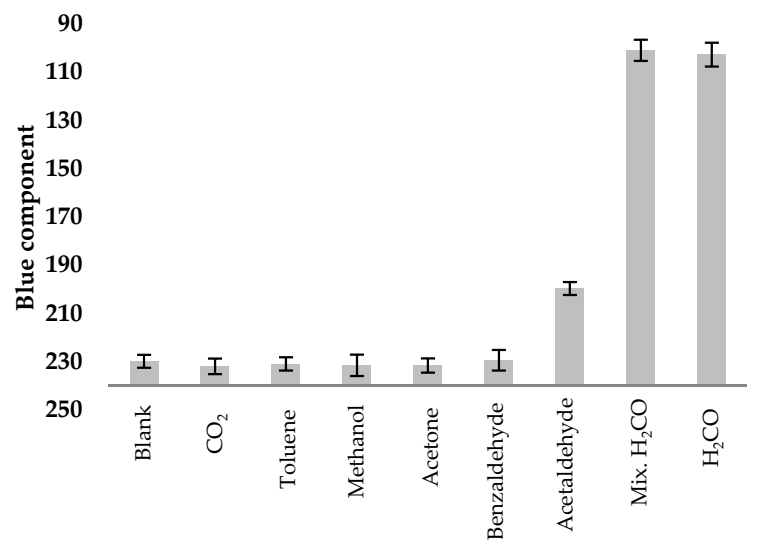

Figure 4. Response of some possible interferents in formaldehyde gas detection. $\mathrm{CO}_{2}(10,000 \mathrm{ppm})$, benzaldehyde (12,000 ppm), acetaldehyde (195,000 ppm), methanol (270,000 ppm), acetone (149,000 ppm), toluene (200,000 ppm) and formaldehyde (3500 ppm).

Table 1. Percentage of variation of the blue component of the probe placed in the dissection room in the absence and in the presence of corpses.

\begin{tabular}{ccc}
\hline Hours & Without Corpses \% Variation & With Corpses \% Variation \\
\hline 24 & $2 \pm 1$ & $3 \pm 1$ \\
48 & $7 \pm 2$ & $10 \pm 2$ \\
\hline
\end{tabular}

The enhancement observed in the percentage of variation in the presence of corpses was around $47 \%$. This increment fits fairly well with the data obtained by the external sensor (Board IFB) placed in the room that measured an increment in formaldehyde concentration around $50 \%$ (See Supplementary Materials). These finding pave the way to the development of personal, cheap and environmentally-friendly chemodosimeters.

\section{Materials and Methods}

\subsection{General Procedures}

All reagents were commercially available and used without purification. Silica gel $60 \mathrm{~F}_{254}$ (Merck, 64293 Darmstadt, Germany) plates were used for test strips. UV/Vis absorption spectra were recorded in a $1 \mathrm{~cm}$ pathlength quartz cuvette with a UV-2101PC spectrophotometer (Shimadzu, 47269 Duisburg, Germany).

\subsection{Preparation of Test Strips}

The probe was prepared by dipping silica-gel plate for $1 \mathrm{~s}$ into a $10^{-1} \mathrm{M}$ solution of dopamine in water containing sucrose ( 0.06 equiv.) and glycine ( 0.1 equiv.) and then air-drying the plate for $45 \mathrm{~min}$. The process was repeated twice before the probe was ready to be used.

\subsection{Gaseous Formaldehyde Measurements}

In a typical assay, the sensing plates were placed in a closed container holding the formaldehyde gas generated from the liquid-vapour equilibrium of formalin diluted solutions at $25{ }^{\circ} \mathrm{C}$, using Henry's law constant to determine the vapour concentrations [39] (see Supplementary Materials for details) for $30 \mathrm{~min}$. In the experiments performed in the dissection room at the Faculty of Medicine, three independent probes for each formaldehyde concentration were used to check the reproducibility of the sensor response. 


\subsection{RGB Analysis}

The results were studied in the computer (ImageJ) using a scanner. For each sample, five different points in the plate were selected to get the average value of the blue component. Then, the percentage of variation (blue component) with respect to the blank was calculated for each formaldehyde concentration. For TWA measurements realized in the Faculty of Medicine of University of Valencia, the percentage of variation (blue component) of each sample respect his own blank were calculated (24 and $48 \mathrm{~h}$ ) to balance out the aging of the silica gel plates.

\section{Conclusions}

In conclusion, we have prepared a new probe able to recognize formaldehyde both in water solution and in the gas phase. The components of the probe-dopamine, glycine and sucrose-are environmentally-friendly compounds when compared to the chemicals used in most of the reported chromo- or fluorogenic formaldehyde tests. In solution both the colour change and fluorescence emission can be used to identify the pollutant compound. The response to formaldehyde gas when the probe is supported on a silica gel plate is colorimetric and can be observed by the naked-eye. Limits of detection for $30 \mathrm{~min}$, STEL and 10-h TWA of 0.7 and $0.4 \mathrm{ppm}$ (below those recommended by NIOSH) were determined, respectively, using simple image-processing software. Finally, the probe has been tested under real conditions in the dissection room at a Faculty of Medicine.

Supplementary Materials: The following are available online. Table S1 Comparative study of the new probe with other previously reported sensors. Figure S1 Influence of $\mathrm{pH}$ on emission, Figure S2 Influence of sucrose on the absorption, Figure S3 Plot of fluorescence intensity at $480 \mathrm{~nm}$ vs. formaldehyde concentration, Figure S4 Protocol for RGB measurements, Figure S5 Plot of percentage of variation of blue component vs. formaldehyde concentration after 30 min exposure, Figure S6 Plot of percentage of variation of blue component vs. formaldehyde concentration after $10 \mathrm{~min}$ exposure and lineal part of the titration, Figure S7 Probes used in the dissection room at the Faculty of Medicine of the University of Valencia after 48 hours. Left: Blank label placed in a formaldehyde clean space. Right: Label placed in the dissection room, Figure S8 Plot of percentage of variation of blue component vs. time of exposition, Figure S9 Register of formaldehyde concentration (in ppm) by the external sensor (Board IFB) in the presence and absence of corpses during the measurement days. Titration studies in solution and calculation of limit of detection. RGB analysis. Titration studies in gas phase. Calculation of limit of detection in gas phase. Interference studies. Formaldehyde emission in real atmospheres contaminated.

Author Contributions: Conceptualization, A.M.C. and P.G.; methodology, C.M.-A. and P.G.; software, C.M.-A. and S.G.; formal analysis, A.M.C., S.G. and P.G.; investigation, C.M.-A.; writing-original draft preparation, C.M.-A.; writing-review and editing, A.M.C. and P.G.

Funding: This research was funded by the Spanish Government (projects MAT2015-64139-C4-4-R and AGL2015-70235-C2-2-R (MINECO/FEDER)) and the Generalitat Valenciana (project PROMETEOII/2014/047).

Acknowledgments: SCSIE (Universidad de Valencia) is gratefully acknowledged for all the equipment employed. We also thank the Department of Anatomy at the Universitat de València for its invaluable help in the measurements made in its dissection room.

Conflicts of Interest: The authors declare no conflict of interest.

\section{References}

1. Merchant Research and Consulting Ltd. Available online: https://mcgroup.co.uk/news/20140627/ formaldehyde-production-exceed-52-mln-tonnes.html (accessed on 5 October 2018).

2. NIOSH. Occupational and Safety and Health Guideline for Formaldehyde. Available online: https://www. cdc.gov/niosh/docs/81-123/pdfs/0293.pdf (accessed on 16 October 2018).

3. Goris, J.A.; Ang, S.; Navarro, C. Laboratory safety: Minimizing the toxic effects of formaldehyde. Lab. Med. 1998, 29, 39-43. [CrossRef]

4. IARC. Chemical Agents and Related Occupations Vol 100 F Review of Human Carcinogens; International Agency for Research on Cancer: Lyon, France, 2012; pp. 401-430.

5. Luo, W.; Li, H.; Zhang, Y.; Ang, C.Y.W. Determination of formaldehyde in blood plasma by high-performance liquid chromatography with fluorescence detection. J. Chromatogr. B 2001, 2, 253-257. [CrossRef] 
6. Rocha, F.R.; Coelho, L.H.G.; Lopes, M.L.A.; Carvalho, L.R.F.; Fracassi da Silva, J.A.; do Lago, C.L.; Gutz, I.G.R. Environmental formaldehyde analysis by active diffusive sampling with a bundle of polypropylene porous capillaries followed by capillary zone electrophoretic separation and contactless conductivity detection. Talanta 2008, 76, 271-275. [CrossRef] [PubMed]

7. Korpan, Y.I.; Gonchar, M.V.; Sibirny, A.A.; Martelet, C.; Elskaya, A.V.; Gibson, T.D.; Soldatkin, A.P. Development of highly selective and stable potentiometric sensors for formaldehyde determination. Biosens. Bioelectron. 2000, 15, 77-83. [CrossRef]

8. Dong, S.; Dasgupta, P.K. Solubility of gaseous formaldehyde in liquid water and generation of trace standard gaseous formaldehyde. Environ. Sci. Technol. 1986, 20, 637-640. [CrossRef] [PubMed]

9. Mitsubayashi, K.; Nishio, G.; Sawai, M.; Saito, T.; Kudo, H.; Saito, H.; Otsuka, K.; Noguer, T.; Marty, I.L. A bio-sniffer stick with FALDH (formaldehyde dehydrogenase) for convenient analysis of gaseous formaldehyde. Sens. Actuator B 2008, 130, 32-37. [CrossRef]

10. Demkiv, O.; Smutok, O.; Paryzhak, S.; Gayda, G.; Sultanov, Y.; Guschin, D.; Shkil, H.; Schuhmann, W.; Gonchar, M. Reagentless amperometric formaldehyde-selective biosensors based on the recombinant yeast formaldehyde dehydrogenase. Talanta 2008, 76, 837-846. [CrossRef] [PubMed]

11. Dennison, M.J.; Hall, J.M.; Turner, A.P.F. Direct monitoring of formaldehyde vapour and detection of ethanol vapour using dehydrogenase-based biosensors. Analyst 1996, 121, 1769-1773. [CrossRef]

12. Wang, X.; Si, Y.; Mao, X.; Li, Y.; Yu, J.; Wang, H.; Ding, B. Colorimetric sensor strips for formaldehyde assay utilizing fluoral-p decorated polyacrylonitrile nanofibrous membranes. Analyst 2013, 138, 5129-5136. [CrossRef] [PubMed]

13. Pinheiro, H.L.C.; de Andrade, M.V.; de Paula Pereira, P.A.; de Andrade, J.B. Spectrofluorimetric determination of formaldehyde in air after collection onto silica cartridges coated with Fluoral P. Microchem. J. 2004, 78, 15-20. [CrossRef]

14. Antwi-Boampong, S.; Peng, J.S.; Carlan, J.; BelBruno, J.J. A molecularly imprinted fluoral-P/polyaniline double layer sensor system for selective sensing of formaldehyde. IEEE Sens. J. 2014, 14, 1490-1498. [CrossRef]

15. Xu, Z.; Chen, J.; Hu, L.-L.; Tan, Y.; Liu, S.-H.; Yin, J. Recent advances in formaldehyde-responsive fluorescent probes. Chin. Chem. Lett. 2017, 28, 1935-1942. [CrossRef]

16. Brewer, T.F.; Chang, C.J. An aza-cope reactivity-based fluorescent probe for imaging formaldehyde in living cells. J. Am. Chem. Soc. 2015, 137, 10886-10889. [CrossRef] [PubMed]

17. Roth, A.; Li, H.; Anorma, C.; Chan, J. A reaction-based fluorescent probe for imaging of formaldehyde in living cells. J. Am. Chem. Soc. 2015, 137, 10890-10893. [CrossRef] [PubMed]

18. Li, J.B.; Wang, Q.Q.; Yuan, L.; Wu, Y.X.; Hu, X.X.; Zhang, X.B.; Tan, W. A two-photon fluorescent probe for bio-imaging of formaldehyde in living cells and tissues. Analyst 2016, 141, 3395-3402. [CrossRef] [PubMed]

19. Tang, Y.; Kong, X.; Xu, A.; Dong, B.; Lin, W. Development of a two-photon fluorescent probe for imaging of endogenous formaldehyde in living tissues. Angew. Chem. Int. Ed. 2016, 55, 3356-3359. [CrossRef] [PubMed]

20. He, L.; Yang, X.; Liu, Y.; Kong, X.; Lin, W. A ratiometric fluorescent formaldehyde probe for bioimaging applications. Chem. Commun. 2016, 52, 4029-4032. [CrossRef] [PubMed]

21. Singha, S.; Jun, Y.W.; Bae, J.; Ahn, K.H. Ratiometric Imaging of Tissue by Two-Photon Microscopy: Observation of a High Level of Formaldehyde around Mouse Intestinal Crypts. Anal. Chem. 2017, 89, 3724-3731. [CrossRef] [PubMed]

22. Song, H.; Rajendiran, S.; Kim, N.; Jeong, S.K.; Ko, E.; Park, R.; Thangadurai, T.D.; Yoon, S. A tailor designed fluorescent 'turn-on' sensor of formaldehyde based on the BODIPY motif. Tetrahedron Lett. 2012, 53, 4913-4916. [CrossRef]

23. Zhou, Y.; Yan, J.; Zhang, N.; Li, D.; Xiao, S.; Zheng, K. A ratiometric fluorescent probe for formaldehyde in aqueous solution, serum and air using aza-cope reaction. Sens. Actuators B Chem. 2018, 258, 156-162. [CrossRef]

24. Chaiendoo, K.; Sooksin, S.; Kulchat, S.; Promarak, V.; Tuntulani, T.; Ngeontae, W. A new formaldehyde sensor from silver nanoclusters modified Tollens' reagent. Food Chem. 2018, 255, 41-48. [CrossRef] [PubMed]

25. Fauzia, V.; Imawan, C.; Kusuma, N.; Narayani, N.M.M.S.; Putri, A.E. A localized surface plasmon resonance enhanced dye-based biosensor for formaldehyde detection. Sens. Actuators B Chem. 2018, 257, 1128-1133. [CrossRef] 
26. El Sayed, S.; Pascual, L.; Licchelli, M.; Martínez-Máñez, R.; Gil, S.; Costero, A.M.; Sancenón, F. Chromogenic Detection of Aqueous Formaldehyde Using Functionalized Silica Nanoparticles. ACS Appl. Mater. Interfaces 2016, 8, 14318-14322. [CrossRef] [PubMed]

27. Li, Z.; Xue, Z.; Wu, X.; Han, J.; Han, S. Chromo-fluorogenic detection of aldehydes with a rhodamine based sensor featuring an intramolecular deoxylactam. Org. Biomol. Chem. 2011, 9, 7652-7654. [CrossRef] [PubMed]

28. Guglielmino, M.; Allouch, A.; Serra, C.A.; Le Calvé, S. Development of microfluidic analytical method for on-line gaseous Formaldehyde detection. Sens. Actuators B Chem. 2017, 243, 963-970. [CrossRef]

29. Xia, H.; Hu, J.; Tang, J.; Xu, K.; Hou, X.; Wu, P. A RGB-Type Quantum Dot-based Sensor Array for Sensitive Visual Detection of Trace Formaldehyde in Air. Sci. Rep. 2016, 6, 36794. [CrossRef] [PubMed]

30. Feng, L.; Musto, C.J.; Suslick, D.S. A Simple and Highly Sensitive Colorimetric Detection Method for Gaseous Formaldehyde. J. Am. Chem. Soc. 2010, 132, 4046-4047. [CrossRef] [PubMed]

31. Guo, X.-L.; Chen, Y.; Jiang, H.-L.; Qiu, X.-B.; Yu, D.-Y. Smartphone-Based Microfluidic Colorimetric Sensor for Gaseous Formaldehyde Determination with High Sensitivity and Selectivity. Sensors 2018, 18, 3141. [CrossRef] [PubMed]

32. He, L.; Yang, X.; Ren, M.; Kong, X.; Liu, Y.; Lin, W. An ultra-fast illuminating fluorescent probe for monitoring formaldehyde in living cells, shiitake mushrooms, and indoors. Chem. Commun. 2016, 52, 9582-9585. [CrossRef] [PubMed]

33. Gangopadhyay, A.; Maiti, K.; Ali, S.S.; Pramanik, A.K.; Guria, U.N.; Samanta, S.K.; Sarkar, R.; Datta, P.; Mahapatra, A.K. A PET based fluorescent chemosensor with real time application in monitoring formaldehyde emissions from plywood. Anal. Methods 2018, 10, 2888-2894. [CrossRef]

34. Lin, Q.; Fan, Y.-Q.; Gong, F.-F.; Mao, P.P.; Wang, J.; Guan, X.-X.; Liu, J.; Zhang, Y.-M.; Yao, H.; Wei, T.-B. Ultrasensitive Detection of Formaldehyde in Gas and Solutions by a Catalyst Preplaced Sensor Based on a Pillar[5]arene Derivative. ACS Sustain. Chem. Eng. 2018, 6, 8775-8781. [CrossRef]

35. Cox, E.D.; Cook, J.M. The Pictet-Spengler condensation: A new direction for an old reaction. Chem. Rev. 1995, 95, 1797-1842. [CrossRef]

36. Jonsson, G. Fluorescence studies on some 6,7-substituted 3,4-dihydroisoquinolines formed from 3-hydroxytyramine (dopamine) and formaldehyde. Acta Chem. Scand. 1966, 20, 2755-2762. [CrossRef] [PubMed]

37. Bjorklund, A.; Ehinger, B.; Falck, B. A method for differentiating dopamine from noradrenaline in tissue sections by microspectrofluorometry. J. Histochem. Cytochem. 1968, 16, 263-270. [CrossRef] [PubMed]

38. Stockigt, J.; Antonchick, A.P.; Wu, F.; Waldmann, H. The Pictet-Spengler reaction in nature and in organic chemistry. Angew. Chem. Int. Ed. 2011, 50, 8538-8564. [CrossRef] [PubMed]

39. Allou, L.; El Maimouni, L.; Le Calvé, S. Henry's law constant measurements for formaldehyde and benzaldehyde as a function of temperature and water composition. Atmos. Environ. 2011, 45, 2991-2998. [CrossRef]

Sample Availability: Samples of the strips are available from the authors.

(C) 2018 by the authors. Licensee MDPI, Basel, Switzerland. This article is an open access article distributed under the terms and conditions of the Creative Commons Attribution (CC BY) license (http:/ / creativecommons.org/licenses/by/4.0/). 